\title{
Healthcare Resource Use and Costs Associated with Opioid Initiation Among Patients with Newly Diagnosed Endometriosis with Commercial Insurance in the USA
}

\author{
Stephanie J. Estes (D) - Ahmed M. Soliman - Marko Zivkovic • \\ Divyan Chopra $\cdot$ Xuelian Zhu
}

Received: March 19, 2020 / Published online: May 12, 2020

(C) The Author(s) 2020

\begin{abstract}
Introduction: To compare all-cause and endometriosis-related healthcare resource utilization (HCRU) and healthcare costs by service categories (outpatient, inpatient, emergency room [ER], pharmacy) among patients with newly diagnosed endometriosis using opioids compared to patients with endometriosis not using opioids.

Methods: A retrospective analysis of IBM ${ }^{\circledR}$ MarketScan ${ }^{\circledR}$ Commercial Claims data from 2009 to 2018 was performed for women aged 18-49 with newly diagnosed endometriosis
\end{abstract}

Digital Features To view digital features for this article go to https://doi.org/10.6084/m9.figshare.12173388.

Electronic Supplementary Material The online version of this article (https://doi.org/10.1007/s12325020-01361-7) contains supplementary material, which is available to authorized users.

\section{S. J. Estes ( $\square)$}

Department of Obstetrics and Gynecology, Penn

State Hershey, Hershey, PA, USA

e-mail: sestes@pennstatehealth.psu.edu

A. M. Soliman

AbbVie, North Chicago, IL, USA

M. Zivkovic $\cdot$ X. Zhu

Genesis Research, Hoboken, NJ, USA

D. Chopra

University of Arkansas for Medical Sciences, Little

Rock, AR, USA
(International Classification of Diseases (ICD)-9 code 617.xx; ICD-10 code N80.xx) over 24 months follow-up. Patients were stratified on the basis of opioid use within 12 months post first endometriosis diagnosis date. Patients with opioid use were 1:1 matched to patients without opioid use using propensity score matching. Results: A total of 85,329 female patients with a new endometriosis diagnosis were identified and 48,470 patients $(24,235$ opioid and 24,235 non-opioid users) remained after inclusion-exclusion criteria and matching. Opioid patients had an estimated mean 30.33 outpatient visits, 29.59 pharmacy fills, 0.28 inpatient visits, 0.65 ER visits, and total length of stay (LOS) was 1.01 days. Non-opioid patients had an estimated mean 27.94 outpatient visits, 22.06 pharmacy fills, 0.23 inpatient visits, 0.42 ER visits, and total LOS was 0.82 days. On average, opioid patients had significantly greater allcause HCRU compared to non-opioid patients (all $p<0.0001$ ). Among endometriosis-related healthcare utilization, there were similar ER visits, but lower outpatient visits, inpatient visits, and total LOS and higher pharmacy fills among opioid and non-opioid patients. Estimated mean all-cause costs were higher among opioid $(\$ 26,755)$ vs. non-opioid $(\$ 19,302)$ users $(p<0.0001)$. A similar trend was observed for estimated mean endometriosis-related costs.

Conclusion: This analysis observed significantly higher all-cause HCRU and costs for opioid users compared to non-opioid users 
among patients with newly diagnosed endometriosis. While observed endometriosisrelated costs were significantly higher in opioid users compared to non-opioid users during a 24-month follow-up period, endometriosis-related HCRU varied by service categories for these two populations over this time period.

Keywords: Cost; Endometriosis; Healthcare resource utilization; Opioid; Pain; Real-world evidence; Women's health

\section{Key Summary Points}

Why carry out this study?

Endometriosis is associated with severe pain and both high direct and indirect costs; although not recommended, opioid use for chronic pain management is frequently observed among patients with endometriosis.

Opioid use among patients with endometriosis could possibly act as a gateway to opioid addiction, opioid-use disorders, illicit opioid use, and even opioid-related overdose deaths, thereby further increasing the healthcare burden.

A retrospective cohort study was conducted to compare all-cause and endometriosis-related healthcare resource utilization and healthcare costs by healthcare services utilization (outpatient, inpatient, emergency room, and pharmacy) among patients with newly diagnosed endometriosis using opioids and those not using opioids.

\section{What was learned from this study?}

Among patients with newly diagnosed endometriosis, those with opioid use within 12 months after first endometriosis diagnosis have more healthcare resource utilization and cost over a 24-month follow-up period, compared to patients not using opioids.
These findings are particularly important because of the ongoing opioid crisis in the USA; prescribers should be aware of increase healthcare resource utilization and costs, in addition to risks that opioids may pose to patients.

Implementation of effective non-opioid strategies for managing chronic pain may help alleviate the excess burden associated with opioid use among patients with endometriosis.

\section{INTRODUCTION}

Endometriosis impacts between $6 \%$ and $10 \%$ of US and European women of reproductive age and is characterized by poor quality of life [1] and severe pain [2-7]. It has been linked to increased direct and indirect costs [8-12]. Allcause annual costs among patients with endometriosis are significantly higher compared to controls $(\$ 11,556-42,020$ vs. \$4315-6124) [9-13]. Significantly higher healthcare resource utilization (HCRU) was also observed in this population, including higher all-cause hospitalizations, endometriosis-related surgical procedures, and visits to the emergency room (ER), outpatient, and obstetrician/gynecologist (OB/GYN) [10, 11, 13, 14].

Guidelines recommend nonsteroidal anti-inflammatory medications (NSAIDs) and hormonal agents as initial components of an endometriosis treatment plan, with gonadotropin-releasing hormone agonists or surgery (laparoscopy with ablation/excision of endometriosis, laparotomy, or hysterectomy) as additional options for treatment that often includes a multidisciplinary approach for patient care [15-18]. Although not included in these recommendations, opioid use for chronic pain management is frequent among this population. Women with endometriosis have been shown to be at greater risk of receiving opioids and to fill a prescription for an opioid [adjusted risk ratio (RR) 2.91] [19, 20]. A 2019 retrospective analysis of women with 
endometriosis found that among opioid users, the average annual number of opioid prescriptions received was 4.6 , with an average day supply of 61.1 days, and $18.1 \%$ of patients received at least 90 days of opioids [21].

Opioid use among patients with endometriosis could possibly act as a gateway to opioid addiction, opioid-use disorders, illicit opioid use, and even opioid-related overdose deaths, thereby increasing the healthcare burden $[22,23]$. With a paucity of literature on the healthcare costs and utilization among women with endometriosis who use opioids, it is of interest to further better understand the impact of opioid utilization on economic burden among patients with endometriosis. Therefore, a retrospective cohort study was conducted to compare all-cause and endometriosis-related healthcare resource utilization (HCRU) and healthcare costs by services utilization (outpatient, inpatient, ER, and pharmacy) among patients with newly diagnosed endometriosis using opioids and those not using opioids.

\section{METHODS}

\section{Data Source}

IBM ${ }^{\circledR}$ MarketScan ${ }^{\circledR}$ Data was used as the primary data source from January 1, 2009 to September 30, 2018 (study period). The Commercial Claims and Encounters database comprises fully adjudicated medical and pharmaceutical claims for over 225 million unique patients from 300 contributing employers and 40 contributing health plans across the USA, which is approximately 62.9 million covered lives per year. It includes inpatient and outpatient diagnoses (in both International Classification of Diseases Ninth (ICD-9) and Tenth (ICD-10) format) and procedures [in Current Procedural Terminology (CPT) and Healthcare Common Procedure Coding System (HCPCS) formats] and both retail and mailorder prescription records. Available data on prescription records include the National Drug Code (NDC), J-codes, as well as the quantity of the medication dispensed. Additional data elements include demographic variables (age, gender, geographic region), health plan type (e.g., health maintenance organization, preferred provider organization), provider specialty, and eligibility dates related to plan enrollment and participation. These data represent commercially insured lives, and data contributors are generally self-insured employers.

This study is based upon claims data. All database records are statistically deidentified and certified to be fully compliant with US patient confidentiality requirements set forth in the Health Insurance Portability and Accountability Act (HIPAA). Because this study used only deidentified patient records and did not involve the collection, use, or transmittal of individually identifiable data, institutional review board approval to conduct this study was not necessary.

\section{Study Design}

A retrospective cohort study of newly diagnosed patients with endometriosis based on a US commercial claims database was conducted. Allcause and endometriosis-related HCRU and healthcare costs were compared between patients with endometriosis with any opioid use and those without opioid use over a 24-month post-index period. Any opioid use in the study considered presence of prescription claims for any opioid medications other than methadone, buprenorphine-naloxone, naloxone, and naltrexone as they are intended for opioid abuse treatment.

\section{Study Population}

Women with newly diagnosed endometriosis (ICD-9 code 617.xx; ICD-10 code N80.xx) between January 1, 2010 and September 30, 2015 were identified, with the first date of endometriosis diagnosis as the cohort entry date. Patients were stratified into opioid users and non-opioid users on the basis of their opioid prescriptions within 12 months following their cohort entry date. For patients with a record of opioid use, the index date is defined as the first opioid prescription date. For patients without a record of opioid use, the index date is defined as the cohort entry date. A minimum 
continuous medical and pharmacy coverage benefits of 12 months prior to and 24 months post index was required for each patient. Patients aged 18-49 at index were included in the analysis.

Patients were excluded if they had a diagnosis of malignant neoplasm anytime during the study period, or had a diagnosis of endometriosis any time prior to the cohort entry date during the study period, or had specific insurance plan types, such as health maintenance organization (HMO) and point of service (POS) with capitation, during the 12-month baseline and 24-month follow-up periods.

\section{Patient Characteristics}

Patient demographic variables measured on the index date included age, region, and insurance type. Medical conditions identified in the 12-month baseline were the Charlson Comorbidity Index (CCI), pain conditions (back/neck pain, joint pain/arthritis, headache/migraine, neuropathic pain, fibromyalgia, other pain conditions including chest/visceral pain/wound/trauma), mental health conditions [anxiety/depression, mood disorders, post-traumatic stress disorder (PTSD), substance-use disorders (SUD)], opioid use, endometriosis-related surgeries, and pregnancy status. CCI is a continuous measure, which was computed using all medical claims (inpatient and outpatient) for 15 conditions (myocardial infarction, congestive heart failure, peripheral vascular disease, cerebrovascular disease, chronic obstructive pulmonary disease, dementia, hemiplegia or paraplegia, diabetes (with and without complications), moderate to severe renal disease, mild and moderate to severe liver disease, peptic ulcer disease, rheumatologic disease, HIV/ AIDS), since patients with malignant neoplasms were excluded from this analysis.

\section{Outcome Measures}

All-cause and endometriosis-related HCRU and costs were evaluated over the 24-month postindex period in total and by utilization category including outpatient, inpatient [including total length of stay (LOS)], ER, and pharmacy. Paid costs along with patient-incurred costs (deductible, copay, coinsurance) were used to identify costs. All costs were adjusted to 2018 costs using the medical component of the Consumer Price Index (CPI).

Adjudicated claims with primary or secondary diagnoses of endometriosis were used to calculate endometriosis-related HCRU and costs [24]. Endometriosis-related pharmacy fills and costs were further specified for drugs primarily used in endometriosis management (danazol, goserelin, leuprolide, nafarelin, estrogen/progestin oral contraceptives).

\section{Statistical Analysis}

Propensity score matching (PSM) was adopted to match patients with opioid use to those without opioid use (1:1 match). PSM was an effective method to facilitate the comparability between patient groups while adjusting for baseline characteristics in retrospective observational studies [25]. In particular, the propensity score in this study was generated using a logistic regression model adjusting for age, region, insurance plan at index date, and CCI, each type of pain and mental health conditions, prior opioid use, prior endometriosis-related surgeries, and pregnancy status observed in the baseline period. A greedy algorithm without replacement technique was applied and the caliper was set a priori at 0.25 standard deviation of propensity score for matching [26].

For patient characteristics, categorical variables were reported as counts and percentages and continuous variables were reported as mean with standard deviation (SD). After matching, a standard mean difference approach was used to check the balance of the characteristics between opioid users and non-opioid users. Patient characteristics with standard mean difference less than 0.1 were considered as balanced between those two groups. For outcome variables, unadjusted HCRU and costs between opioid user and non-opioid users after matching were evaluated using the paired $t$ test.

Multivariable regression analyses were used to produce adjusted results for all outcomes of 
interest. Covariates included propensity score, index year, and the corresponding baseline outcome. Patient characteristics with standard mean difference greater than 0.1 after matching were also included in the regression models. The generalized estimating equations (GEE) method was incorporated in adjusted analysis due to matching. For HCRU outcomes, generalized linear models (GLM) with negative binomial (NB) distribution and log link function were conducted. For all-cause costs, GLM with gamma distribution and log link function were applied to estimated mean costs. For patients with zero cost claim records, a $\$ 1$ cost was added in order to include all patients into the analysis. Estimated mean ratio with 95\% confidence intervals (CIs) were also reported [27]. A two-part model was used to estimate mean endometriosis-related costs, because of more than $10 \%$ of patients with zero endometriosis-related costs. The first-part model was to estimate the probability of having non-zero costs among all patients and the second-part model estimated the mean costs among patients who have non-zero costs [28]. The final estimated mean endometriosis-related costs equals the product of the probability of having non-zero costs and the estimated mean costs for patients with non-zero costs. Lastly, 95\% CIs for the estimated mean ratios between opioid users and non-opioid users were generated using a bootstrapping method (repeated for 500 times).

All statistical analyses were performed using SAS version 9.4 (SAS, Cary, NC). Statistical significance was determined by $p<0.05$.

\section{RESULTS}

\section{Study Sample}

Initially, a total of 85,329 female patients with newly diagnosed endometriosis were identified from the commercial claims database (Fig. 1), of whom 61,019 (71.5\%) were opioid users and $24,310(28.5 \%)$ were non-opioid users. After matching, 24,235 matched pairs were included in this analysis.

\section{Patient and Clinical Characteristics}

Patient characteristics are presented in Table 1. Patients with opioid use had a lower standard mean age compared to those without opioid use $(37.4 \pm 7.3$ vs $38.4 \pm 7.4$ years, standard mean difference 0.1395) and equivalent CCI scores $(0.19 \pm 0.5$, standard mean difference $-0.0046)$ were observed between them. More than $40 \%$ of these patients lived in the South (opioid users $44.8 \%$, non-opioid users $40.2 \%$ ) and around $71 \%$ of them had a preferred provider organization (PPO) insurance plan (opioid users 71.7\%, non-opioid users 70.6\%). A similar number of standard mean pain conditions $(0.85 \pm 1.01$ vs. $0.81 \pm 1.02)$ and mental health conditions $(0.23 \pm 0.58$ vs. $0.22 \pm 0.58)$ were noted among patients with or without opioid use. In addition, the matched cohorts had close percentages of opioid use $(36.7 \%$ vs. $33.0 \%$, standard mean difference 0.0769) and endometriosis-related surgeries $(5.4 \%$ vs. $5.3 \%$, standard mean difference 0.0005 ) in the baseline period.

\section{Healthcare Resource Utilization}

Across all service categories, multivariable regression analyses demonstrated that all-cause HCRU over the 24-month post-index period was significantly higher for opioid users compared to non-opioid users (Fig. 2 and Table 2).

Estimated mean all-cause outpatient visits per patient among opioid users were higher than those for non-opioid users (30.33 vs. 27.94, mean ratio 1.09). Estimated mean allcause ER visits per patient were 0.65 and 0.42 for opioid and non-opioid users, respectively (mean ratio 1.53). All-cause inpatient visits per patient for opioid users were greater than those for non-opioid users (estimated mean 0.28 vs. 0.23 , mean ratio 1.23 ), along with longer total LOS (estimated mean 1.01 vs. 0.82 days, mean ratio 1.23). On average, all-cause pharmacy fills among opioid users were 29.59 compared to 22.06 among non-opioid users (mean ratio 1.34). All comparisons were significant $(p<0.0001)$. 


\begin{tabular}{|c|c|c|c|}
\hline \multicolumn{2}{|r|}{ Inclusion Criteria } & $\begin{array}{l}\text { Number of } \\
\text { unique patients }\end{array}$ & $\begin{array}{l}\text { Percentage } \\
\text { (\%) }\end{array}$ \\
\hline 1 & $\begin{array}{l}\text { Female patients with an endometriosis diagnosis in the cohort identification } \\
\text { period (Jan 1, } 2010 \text { - Sep 30, 2015). The cohort entry date is defined as the } \\
\text { first endometriosis diagnosis date. }\end{array}$ & 599,680 & $100 \%$ \\
\hline $1 a$ & $\begin{array}{l}\text { Patients with a record of opioids use within 12-month post the cohort entry } \\
\text { date. The index date is defined as the first opioid prescription date. }\end{array}$ & 312,481 & $52.1 \%$ \\
\hline $1 b$ & $\begin{array}{l}\text { Patients without a record of opioids use within 12-month post the cohort } \\
\text { entry date. The index date is defined as cohort entry date. }\end{array}$ & 287,199 & $47.9 \%$ \\
\hline 2 & $\begin{array}{l}\text { Patients with at least } 12 \text {-month continuous pharmacy and medical benefits } \\
\text { prior to the index date. }\end{array}$ & 308,749 & $51.5 \%$ \\
\hline 3 & $\begin{array}{l}\text { Patients with at least } 24 \text {-month continuous pharmacy and medical benefits } \\
\text { post the index date. }\end{array}$ & 152,737 & $25.5 \%$ \\
\hline 4 & Patients aged between 18 and 49 at the index date & 123,423 & $20.6 \%$ \\
\hline \multicolumn{4}{|c|}{ Exclusion Criteria } \\
\hline 5 & $\begin{array}{l}\text { Exclude patients with a diagnosis of malignant neoplasm anytime during the } \\
\text { study period }\end{array}$ & 110,678 & $18.5 \%$ \\
\hline 6 & $\begin{array}{l}\text { Exclude patients with a diagnosis of endometriosis any time prior to the } \\
\text { cohort entry date during the study period }\end{array}$ & 102,220 & $17.0 \%$ \\
\hline 7 & $\begin{array}{l}\text { Exclude patients with specific insurance plan types* during the 12-month } \\
\text { baseline period and } 24 \text {-month follow-up period }\end{array}$ & 85,329 & $14.2 \%$ \\
\hline
\end{tabular}

Fig. 1 Cohort attrition table. * Patients with plan types health maintenance organization (HMO) and point of service (POS) with capitation were excluded from this analysis

Pharmacy fills were the only endometriosisrelated HCRU that was significantly higher for opioid users compared to non-opioid users (0.36 vs. 0.29 , mean ratio $1.26, p<0.0001)$. Estimated mean endometriosis-related ER visits were similar between patient with opioid use and those without opioid use (0.027 vs. 0.026 , mean ratio $1.03, p=0.6525)$. Endometriosis-related outpatient visits, inpatient visits, and total LOS for opioid users were significantly less than those for non-opioid users (outpatient 1.73 vs. 1.82, mean ratio 0.95 ; inpatient 0.05 vs. 0.07 , mean ratio 0.74 ; total LOS 0.17 vs. 0.22 , mean ratio 0.77$)$.

Similar trends were observed for unadjusted all-cause and endometriosis-related HCRU, except for unadjusted endometriosis-related outpatient visits (Table S1 in the supplementary material). On average, patients with opioid use had higher HCRU compared to patients without opioid use.

\section{Healthcare Costs}

Results from multivariable regression analyses indicated that estimated mean costs over the 24-month post-index period were higher for opioid users compared to non-opioid users (Table 3).

Estimated mean all-cause healthcare costs among opioid users were higher than those for non-opioid users $(\$ 26,755$ vs. $\$ 19,302$, mean ratio 1.39). Medical costs were the largest cost driver, accounting for $88.3 \%$ of costs among opioid users and $86.8 \%$ of total costs among non-opioid users. Estimated mean medical costs were higher among opioid users $(\$ 23,615)$ compared to non-opioid users $(\$ 16,752$, mean ratio 1.41). Estimated mean pharmacy costs for opioid users were greater than those for nonopioid users (estimated mean $\$ 2728$ vs. \$2110, mean ratio 1.29). All the comparisons were significant $(p<0.0001)$.

Estimated mean endometriosis-related healthcare costs among opioid users were higher than those for non-opioid users ( $\$ 8629$ vs. $\$ 5792$, mean ratio 1.49$)$. Medical costs 
Table 1 Baseline characteristics for patients with endometriosis after matching

\begin{tabular}{|c|c|c|c|c|c|}
\hline \multirow[t]{2}{*}{ Characteristic } & \multicolumn{2}{|c|}{ Patients with opioid use } & \multicolumn{2}{|c|}{ Patients without opioid use } & \multirow[t]{2}{*}{ Standard mean difference } \\
\hline & $N$ & $\%$ & $N$ & $\%$ & \\
\hline Number of unique patients & 24,235 & $100 \%$ & 24,235 & $100 \%$ & \\
\hline \multicolumn{6}{|l|}{ Age group at index } \\
\hline $18-29$ & 3509 & $14.5 \%$ & 3061 & $12.6 \%$ & N/A \\
\hline $30-39$ & 10,353 & $42.7 \%$ & 8930 & $36.8 \%$ & N/A \\
\hline $40-49$ & 10,373 & $42.8 \%$ & 12,244 & $50.5 \%$ & N/A \\
\hline \multicolumn{6}{|l|}{ Age at index } \\
\hline Mean (SD) & 37.4 & 7.3 & 38.4 & 7.4 & 0.1395 \\
\hline \multicolumn{6}{|l|}{ Region at index } \\
\hline Northeast & 4257 & $17.6 \%$ & 5525 & $22.8 \%$ & $\mathrm{~N} / \mathrm{A}$ \\
\hline North Central & 5176 & $21.4 \%$ & 4751 & $19.6 \%$ & N/A \\
\hline South & 10,852 & $44.8 \%$ & 9736 & $40.2 \%$ & N/A \\
\hline West & 3798 & $15.7 \%$ & 4056 & $16.7 \%$ & N/A \\
\hline Unknown & 152 & $0.6 \%$ & 167 & $0.7 \%$ & $\mathrm{~N} / \mathrm{A}$ \\
\hline \multicolumn{6}{|l|}{ Plan type at index } \\
\hline Comprehensive & 314 & $1.3 \%$ & 324 & $1.3 \%$ & N/A \\
\hline EPO & 362 & $1.5 \%$ & 409 & $1.7 \%$ & $\mathrm{~N} / \mathrm{A}$ \\
\hline POS & 2128 & $8.8 \%$ & 2131 & $8.8 \%$ & $\mathrm{~N} / \mathrm{A}$ \\
\hline $\mathrm{PPO}$ & 17,381 & $71.7 \%$ & 17,102 & $70.6 \%$ & $\mathrm{~N} / \mathrm{A}$ \\
\hline CDHP & 2245 & $9.3 \%$ & 2200 & $9.1 \%$ & $\mathrm{~N} / \mathrm{A}$ \\
\hline HDHP & 1075 & $4.4 \%$ & 1181 & $4.9 \%$ & $\mathrm{~N} / \mathrm{A}$ \\
\hline Unknown & 730 & $3.0 \%$ & 888 & $3.7 \%$ & $\mathrm{~N} / \mathrm{A}$ \\
\hline \multicolumn{6}{|c|}{ Charlson Comorbidity Index (CCI) score } \\
\hline Mean (SD) & 0.19 & 0.51 & 0.19 & 0.52 & -0.0046 \\
\hline \multicolumn{6}{|c|}{ Number of pain conditions (based on the following five pain categories) } \\
\hline Mean (SD) & 0.85 & 1.01 & 0.81 & 1.02 & $\mathrm{~N} / \mathrm{A}$ \\
\hline \multicolumn{6}{|c|}{ Number of patients with back/neck pain } \\
\hline Yes & 6218 & $25.7 \%$ & 5866 & $24.2 \%$ & 0.0326 \\
\hline No & 18,017 & $74.3 \%$ & 18,369 & $75.8 \%$ & \\
\hline \multicolumn{6}{|c|}{ Number of patients with joint pain/arthritis } \\
\hline Yes & 7912 & $32.6 \%$ & 7651 & $31.6 \%$ & 0.0227 \\
\hline No & 16,323 & $67.4 \%$ & 16,584 & $68.4 \%$ & \\
\hline
\end{tabular}


Table 1 continued

\section{Characteristic}

\section{Patients with opioid use

$\bar{N} \%$

\section{Patients without opioid use

N \%

Number of patients with headache/migraine

$\begin{array}{llllll}\text { Yes } & 1523 & 6.3 \% & 1501 & 6.2 \% & 0.0033 \\ \text { No } & 22,712 & 93.7 \% & 22,734 & 93.8 \% & \end{array}$

Number of patients with neuropathic pain

$\begin{array}{llllll}\text { Yes } & 718 & 3.0 \% & 685 & 2.8 \% & 0.0075 \\ \text { No } & 23,517 & 97.0 \% & 23,550 & 97.2 \% & \end{array}$

Number of patients with fibromyalgia

$\begin{array}{llllll}\text { Yes } & 1059 & 4.4 \% & 1026 & 4.2 \% & 0.0061 \\ \text { No } & 23,176 & 95.6 \% & 23,209 & 95.8 \% & \end{array}$

Number of patients with other pain conditions (chest/visceral pain/wound/trauma)

$\begin{array}{llllll}\text { Yes } & 3113 & 12.8 \% & 2947 & 12.2 \% & 0.0191 \\ \text { No } & 21,122 & 87.2 \% & 21,288 & 87.8 \% & \end{array}$

Number of mental health conditions (based on the following four mental health categories)
Mean (SD)
0.23
0.58
0.22
0.58
N/A

Number of patients with anxiety/depression

$\begin{array}{llllll}\text { Yes } & 3406 & 14.1 \% & 3284 & 13.6 \% & 0.0134 \\ \text { No } & 20,829 & 85.9 \% & 20,951 & 86.4 \% & \end{array}$

Number of patients with mood disorders

$\begin{array}{llllll}\text { Yes } & 1953 & 8.1 \% & 1866 & 7.7 \% & 0.0118 \\ \text { No } & 22,282 & 91.9 \% & 22,369 & 92.3 \% & \end{array}$

Number of patients with post-traumatic stress disorder (PTSD)

$\begin{array}{llllll}\text { Yes } & 133 & 0.5 \% & 137 & 0.6 \% & -0.0020 \\ \text { No } & 24,102 & 99.5 \% & 24,098 & 99.4 \% & \end{array}$

Number of patients with substance-use disorder (SUD)

$\begin{array}{llllll}\text { Yes } & 85 & 0.4 \% & 90 & 0.4 \% & -0.0025 \\ \text { No } & 24,150 & 99.6 \% & 24,145 & 99.6 \% & \end{array}$

Number of patients with prior opioid use

$\begin{array}{llllll}\text { Yes } & 8902 & 36.7 \% & 8000 & 33.0 \% & 0.0769 \\ \text { No } & 15,333 & 63.3 \% & 16,235 & 67.0 \% & \end{array}$

Number of patients with prior endometriosis-related surgery 
Table 1 continued

\begin{tabular}{|c|c|c|c|c|c|}
\hline \multirow[t]{2}{*}{ Characteristic } & \multicolumn{2}{|c|}{ Patients with opioid use } & \multicolumn{2}{|c|}{ Patients without opioid use } & \multirow[t]{2}{*}{ Standard mean difference } \\
\hline & $\bar{N}$ & $\%$ & $\bar{N}$ & $\%$ & \\
\hline Yes & 1303 & $5.4 \%$ & 1295 & $5.3 \%$ & 0.0005 \\
\hline No & 22,935 & $94.6 \%$ & 22,940 & $94.7 \%$ & \\
\hline \multicolumn{6}{|c|}{ Number of patients with pregnancy } \\
\hline Yes & 1539 & $6.4 \%$ & 1366 & $5.6 \%$ & 0.0310 \\
\hline No & 22,696 & $93.6 \%$ & 22,869 & $94.4 \%$ & \\
\hline
\end{tabular}

$C D H P$ consumer-driven health plan, $E P O$ exclusive provider organization, $H D P H$ high deductible health plan, $P O S$ pointof-service, $P P O$ preferred provider organization, $S D$ standard deviation

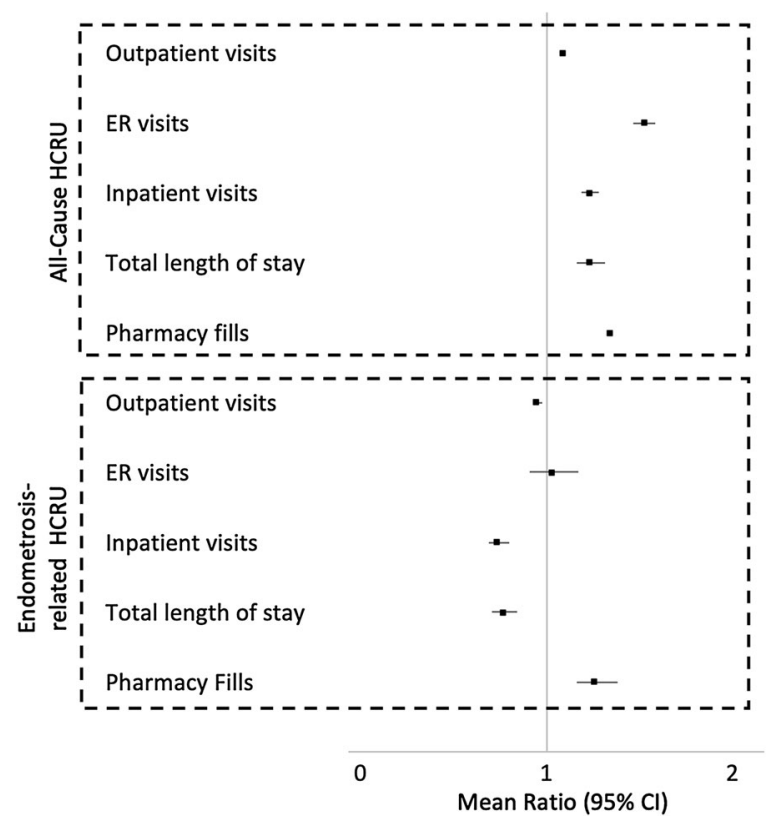

Fig. 2 Adjusted mean ratio with 95\% CI for HCRU by service category. $H C R U$ healthcare resource utilization, $C I$ confidence interval, ER emergency room

accounted for $97.5 \%$ and $97.9 \%$ of total costs among opioid and non-opioid users (\$8411 vs. $\$ 5669$, mean ratio 1.48$)$. Estimated mean pharmacy costs were greater among opioid compared to non-opioid users (\$174 vs. \$116, mean ratio 1.50 ).

The unadjusted all-cause and endometriosisrelated healthcare costs are summarized in Table S2 in the supplementary material. On average, opioid users had higher all-cause and endometriosis-related healthcare costs compared to non-opioid users, except for unadjusted endometriosis-related inpatient costs. All comparisons were significant.

\section{DISCUSSION}

Both all-cause HCRU and costs for patients with endometriosis with opioid use during a 24-month follow-up period were significantly higher than those for matched patients with endometriosis without opioid use, indicating that opioid-using patients with endometriosis have higher total healthcare burden. The increase in all-cause HCRU among opioid user vs. non-opioid users was consistent across different service categories. These observed HCRU trends are consistent with prior endometriosis literature on newly diagnosed patients, where significantly higher HCRU, including higher allcause hospitalizations, ER visits, physician visits, and outpatient visits, has been observed $[10,14,29]$. The high outpatient visit utilization observed in this study suggests that primary endometriosis management is in the outpatient setting. Outpatient visits and pharmacy fills were also the largest contributors to HCRU. Although this study could not discern the reason for prescribing the opioids to the analyzed population of patients with endometriosis, the difference in all-cause healthcare utilization between opioid users and non-opioid users was particularly pronounced in ER visits (mean ratio 
Table 2 Adjusted HCRU for patients with endometriosis after matching

\begin{tabular}{|c|c|c|c|c|}
\hline Characteristics & $\begin{array}{l}\text { Estimated mean for patients } \\
\text { with opioid use }\end{array}$ & $\begin{array}{l}\text { Estimated mean for patients } \\
\text { without opioid use }\end{array}$ & $\begin{array}{l}\text { Estimated mean ratio } \\
(95 \% \mathrm{CI})\end{array}$ & $p$ value \\
\hline \multicolumn{5}{|l|}{ All-cause HCRU } \\
\hline $\begin{array}{l}\text { Outpatient } \\
\text { visits }\end{array}$ & 30.33 & 27.94 & $1.09(1.07-1.10)$ & $<0.0001$ \\
\hline ER visits & 0.65 & 0.42 & $1.53(1.47-1.58)$ & $<0.0001$ \\
\hline $\begin{array}{l}\text { Inpatient } \\
\text { visits }\end{array}$ & 0.28 & 0.23 & $1.23(1.19-1.28)$ & $<0.0001$ \\
\hline Total LOS & 1.01 & 0.82 & $1.23(1.16-1.31)$ & $<0.0001$ \\
\hline Pharmacy fills & 29.59 & 22.06 & $1.34(1.32-1.36)$ & $<0.0001$ \\
\hline \multicolumn{5}{|c|}{ Endometriosis-related HCRU } \\
\hline $\begin{array}{l}\text { Outpatient } \\
\text { visits }\end{array}$ & 1.73 & 1.82 & $0.95(0.93-0.98)$ & 0.0003 \\
\hline ER visits & 0.027 & 0.026 & $1.03(0.91-1.17)$ & 0.6525 \\
\hline $\begin{array}{l}\text { Inpatient } \\
\text { visits }\end{array}$ & 0.05 & 0.07 & $0.74(0.69-0.80)$ & $<0.0001$ \\
\hline Total LOS & 0.17 & 0.22 & $0.77(0.71-0.84)$ & $<0.0001$ \\
\hline Pharmacy fills & 0.36 & 0.29 & $1.26(1.16-1.38)$ & $<0.0001$ \\
\hline
\end{tabular}

HCRU healthcare resource utilization, $C I$ confidence interval, ER emergency room, LOS length of stay

Table 3 Adjusted costs for patients with endometriosis after matching

\begin{tabular}{lllll}
\hline Characteristics & $\begin{array}{l}\text { Estimated mean for patients } \\
\text { with opioid use }\end{array}$ & $\begin{array}{l}\text { Estimated mean for patients } \\
\text { without opioid use }\end{array}$ & $\begin{array}{l}\text { Estimated mean ratio } \\
(\mathbf{9 5 \%} \text { CI) }\end{array}$ & $\boldsymbol{p}$ value \\
\hline $\begin{array}{l}\text { All-cause costs } \\
\text { Total }\end{array}$ & $\$ 26,755$ & $\$ 19,302$ & $1.39(1.36-1.41)$ & $<0.0001$ \\
Medical & $\$ 23,615$ & $\$ 16,752$ & $1.41(1.38-1.44)$ & $<0.0001$ \\
Pharmacy & $\$ 2728$ & $\$ 2110$ & $1.29(1.23-1.36)$ & $<0.0001$ \\
Endometriosis-related costs & & & \\
Total & $\$ 8629$ & $\$ 5792$ & $1.49(1.45-1.54)$ & N/A \\
Medical & $\$ 8411$ & $\$ 5669$ & $1.48(1.44-1.53)$ & N/A \\
Pharmacy & $\$ 174$ & $\$ 116$ & $1.50(1.34-1.67)$ & N/A \\
\hline
\end{tabular}

CI confidence interval

1.53), possibly pointing to additional underlying conditions or an insufficient management of symptoms among the opioid-using population requiring frequent ER visits. Similarly, the 
extent of difference in all-cause prescription fills between two populations (mean ration 1.34) can be understood, in addition to the intrinsically higher opioid prescription fills among the opioid users, potentially as the difference due to the use of prescriptions for other underlying conditions.

However, endometriosis-related HCRU varied by service categories between the populations of opioid-using and non-opioid-using patients with endometriosis during this time period. Opioid users had higher pharmacy fills, but lower outpatient, inpatient visits, and total LOS compared to non-opioid users, while similar ER utilization was observed among opioid and non-opioid users. The higher endometriosis-related pharmacy fills among opioid users compared to non-opioid users (mean ratio 1.26) suggests a correlation between opioid use and increase in endometriosis disease-modifying drugs.

Further, all-cause healthcare utilization was greater compared to endometriosis-related healthcare utilization. The observed magnitude difference in all-cause and endometriosis-related HCRU across each service category can in part be explained by difference in scope of disease management included in the analysis of utilization. For example, pharmacy fill trend aligns with these expectations, as the endometriosis-related pharmacy fills were defined with specific medications (including danazol, goserelin, leuprolide, nafarelin, estrogen/progestin oral contraceptives), while allcause pharmacy fills represented both opioids and other indications' non-opioid medications.

All-cause total, medical, and pharmacy costs for opioid users were significantly higher than costs for non-opioid users according to both unadjusted and adjusted multivariable analyses. Medical costs accounted for $88.3 \%$ and $86.8 \%$ of total costs among opioid users and non-opioid users, respectively. All-cause costs for opioid users were driven by outpatient costs $(66 \%)$, followed by inpatient (16\%), pharmacy (14\%), and ER costs (3\%). Similar patterns were observed for non-opioid users.

Endometriosis-related costs were also higher among opioid users compared to non-opioid users ( $\$ 360$ vs. $\$ 241$ per person per month,
PPPM). Endometriosis-related medical costs accounted for nearly all of the total costs; $97.5 \%$ and $97.9 \%$ of total costs among opioid and nonopioid users, respectively. One reason may be that opioid costs were not included in endometriosis-related cost calculations.

Estimated total all-cause costs from this analysis aligned with the literature; patients with opioid use incurred higher costs $(\$ 1115$ PPPM) compared to patients without opioid use (\$804 PPPM). Existing literature found total costs of endometriosis ranged between $\$ 963$ and \$3502 PPPM [9-13]. A recent analysis by AsSanie et al. assessed the economic burden among opioid users [29]. They also found significantly higher all-cause HCRU and costs in patients with endometriosis with opioid use compared to those without opioid use. For example, total annual all-cause healthcare costs for patients with endometriosis using opioids were higher than for those without opioid use (mean \$29,236 vs. \$18,446) [29]. Results from this analysis also aligned with As-Sanie et al. with respect to cost driver mix, where a majority of opioid user costs were outpatient, followed by inpatient and pharmacy costs [29]. However, their mean annual costs among opioid users were higher than those in this study $(\$ 29,236$ vs. $\$ 26,755)$, which might be caused by several reasons. First, the costs were evaluated within the 24-month post-index period in this study, compared to 12-month post-index in As-Sanie's analysis. The index date for patients with opioid use in this study was their first opioid prescription date after endometriosis diagnosis, while As-Sanie used the endometriosis diagnosis date. It was reported that patients with endometriosis have the highest costs in the first year after diagnosis, partly due to more surgeries in the year after diagnosis [30]. Second, there are prominent differences between the matched populations used for analysis in these two studies. For example, populations in As-Sanie et al.'s analysis have higher hospital admissions (0.42 and 0.30) compared to those in this study (0.28 and 0.23 ) for patients with/without opioid use, respectively.

Something of note in this study is the high proportion of women with endometriosis who reported opioid use. Out of the initial 85,329 
female patients with newly diagnosed endometriosis, $71.5 \%$ were opioid users and $28.5 \%$ were non-opioid users. In comparison, patients diagnosed with other diseases reported lower percentages of opioid use: complex regional pain syndrome $(7.5 \%)$, trauma (13.9\%), post-surgical (6.9\%), spondylosis (1.8\%), failed back surgery syndrome (4.6\%), and other chronic pain (7.3\%) [30, 31]. Another study reported that a third of patients received an opioid prescription within 6 weeks for acute low back pain [31]. In England, 1.9\% of patients receive opioids for chronic pain [32]. In Australia, $0.7 \%$ and $2.6 \%$ of pregnant and nonpregnant women with chronic or reoccurring pain reported recent opioid use, respectively [33].

The findings of this study are particularly important because of the ongoing opioid crisis in the USA. Prescribers should be aware of increase HCRU and costs, in addition to risks that opioids may pose to patients. Implementation of effective non-opioid strategies for managing chronic pain may help alleviate the excess burden associated with opioid use among patients with endometriosis.

A strength of this analysis is that it included a large cohort of patients with opioid use and matched patients without opioid use to evaluate the costs and healthcare utilization. Further, the controls in this analysis are patients with endometriosis, unlike the existing endometriosis literature which has previously used patients without endometriosis [9-14, 34-36]. Finally, this study utilizes a geographically diverse commercial database.

This study has several limitations inherent to claims data analyses. The findings of this study are limited to the IBM ${ }^{\circledR}$ MarketScan ${ }^{\circledR}$ commercial population and may not be generalizable to the entire USA or other countries. Claims data do not allow use of certain demographic and clinical variables such as race, pain, and endometriosis severity. This analysis does not capture opioid prescriptions paid for by cash or illicitly obtained for or administered during an inpatient study. Upcoding or miscoding may not reflect actual estimations and the analysis can only identify prescriptions filled and not prescriptions taken. The statistical differences do not imply clinical differences. Zero cost was observed for some patients in the cohort, which might be caused by billing error or claims adjustment in the database. The uncertainty of this may underestimate the true healthcare costs. However, appropriate modelling techniques were adopted to minimize the bias. Finally, causal inference cannot be readily drawn from this analysis considering the intrinsic observational study design.

\section{CONCLUSION}

This study provides detailed information on the economic burden associated with opioid use among patients with newly diagnosed endometriosis. Results demonstrate significantly higher all-cause HCRU and costs for patients with endometriosis with opioid use during a 24-month follow-up period than those for matched patients with endometriosis without opioid use. Pain management is a backbone of maintaining patient quality of life (QoL), as well as long-term outcomes in endometriosis [4]. With the more broadly recognized challenges associated with long-term opioid use, it is important to also understand reduced pain management strategy effectiveness and any potential risk indicators for patient safety.

\section{ACKNOWLEDGEMENTS}

Funding. This study, the Rapid Service and Open Access Fees were funded by AbbVie. AbbVie participated in developing the study design, data analysis and interpretation, manuscript writing and revisions, and approval for publication.

Medical Writing and Editorial Assistance. Editorial/medical writing support for this manuscript was provided by Patrick Callahan, PharmD, MS and Nicole Safran, MPH, employees of Genesis Research, and funded by AbbVie. 
Authorship. All named authors meet the International Committee of Medical Journal Editors (ICMJE) criteria for authorship for this article, take responsibility for the integrity of the work as a whole, and have given their approval for this version to be published.

Disclosures. Stephanie J. Estes is a paid consultant for AbbVie Inc, provides AbbVie Inc. with research support and participates in their Speaker's Bureau and provides research support for ObsEva and Ferring. Ahmed M. Soliman is an employee of and own stock/stock options in AbbVie. Marko Zivkovic is an employee of Genesis Research and was a paid consultant for AbbVie Inc. Xuelian Zhu is an employee of Genesis Research and was a paid consultant for AbbVie Inc. Divyan Chopra is a paid contractor with AbbVie Inc and affiliated with university of Arkansas for Medical sciences. The study sponsor is funding the journal's Rapid Service and Open Access Fees.

Compliance with Ethics Guidelines. This study is based upon claims data. All database records are statistically deidentified and certified to be fully compliant with US patient confidentiality requirements set forth in the Health Insurance Portability and Accountability Act (HIPAA). Because this study used only deidentified patient records and did not involve the collection, use, or transmittal of individually identifiable data, institutional review board approval to conduct this study was not necessary.

Data Availability. The datasets generated during and/or analyzed during the current study are available in the IBM ${ }^{\circledR}$ MarketScan ${ }^{\circledR}$ repository, https://www.ibm.com/products/ marketscan-research-databases.

Open Access. This article is licensed under a Creative Commons Attribution-NonCommercial 4.0 International License, which permits any non-commercial use, sharing, adaptation, distribution and reproduction in any medium or format, as long as you give appropriate credit to the original author(s) and the source, provide a link to the Creative Commons licence, and indicate if changes were made. The images or other third party material in this article are included in the article's Creative Commons licence, unless indicated otherwise in a credit line to the material. If material is not included in the article's Creative Commons licence and your intended use is not permitted by statutory regulation or exceeds the permitted use, you will need to obtain permission directly from the copyright holder. To view a copy of this licence, visit http://creativecommons.org/licenses/by$\mathrm{nc} / 4.0 /$.

\section{REFERENCES}

1. Ferreira ALL, Bessa MMM, Drezett J, De Abreu LC. Quality of life of the woman carrier of endometriosis: systematized review. Reprod Clim. 2016;31(1):48-54.

2. Morotti M, Vincent K, Becker CM. Mechanisms of pain in endometriosis. Eur J Obstet Gynecol Reprod Biol. 2017;209:8-13.

3. Vercellini $\mathrm{P}$, Viganò $\mathrm{P}$, Somigliana $\mathrm{E}$, Fedele L. Endometriosis: pathogenesis and treatment. Nat Rev Endocrinol. 2014;10(5):261-75.

4. Bourdel N, Chauvet P, Billone V, et al. Systematic review of quality of life measures in patients with endometriosis. PLoS One. 2019;14(1):e0208464. https://doi.org/10.1371/journal.pone.0208464.

5. Eskenazi B, Warner ML. Epidemiology of endometriosis. Obstet Gynecol Clin North Am. $1997 ; 24(2): 235-58$.

6. American College of Obstetricians and Gynecologists (ACOG). Practice Bulletin No. 114: management of endometriosis. Obstet Gynecol. 2010;116(1):223-36. https://content.wkhealth. com/linkback/openurl?sid=WKPTLP: landingpage\&an=00006250-201007000-00041

7. Dunselman GAJ, Vermeulen N, Becker C, et al. ESHRE guideline: management of women with endometriosis. Hum Reprod. 2014;29(3):400-12. https://doi.org/10.1093/humrep/det457.

8. Soliman AM, Coyne KS, Gries KS, Castelli-Haley J, Snabes MC, Surrey ES. The effect of endometriosis symptoms on absenteeism and presenteeism in the workplace and at home. J Manag Care Spec Pharm. 201723(7):745-54. 
9. Soliman AM, Surrey E, Bonafede M, Nelson JK, Castelli-Haley J. Real-world evaluation of direct and indirect economic burden among endometriosis patients in the United States. Adv Ther. 2018;35(3): 408-23.

10. Fuldeore M, Yang H, Du EX, Soliman AM, Wu EQ, Winkel C. Healthcare utilization and costs in women diagnosed with endometriosis before and after diagnosis: a longitudinal analysis of claims databases. Fertil Steril. 2015;103(1):163-71.

11. Estes SJ, Soliman AM, Epstein AJ, Bond JC, Gordon $\mathrm{K}$, Missmer SA. National trends in inpatient endometriosis admissions: patients, procedures and outcomes, 2006-2015. PLoS One. 2019;14(9): e0222889.

12. Soliman AM, Surrey ES, Bonafede M, Nelson JK, Vora JB, Agarwal SK. Health care utilization and costs associated with endometriosis among women with Medicaid insurance. J Manag Care Spec Pharm. 2019;25(5):566-72.

13. Mirkin D, Murphy-Barron C, Iwasaki K. Actuarial analysis of private payer administrative claims data for women with endometriosis. J Manag Care Pharm. 2007;13(3):262-72.

14. Soliman AM, Surrey E, Bonafede M, Nelson JK, Castelli-Haley J. Real-world evaluation of direct and indirect economic burden among endometriosis patients in the United States. Adv Ther. 2018;35(3): 408-23.

15. The Practice Committee of the American Society for Reproductive Medicine. Treatment of pelvic pain associated with endometriosis: a committee opinion. Fertil Steril. 2014;101:927-35.

16. Committee on Adolescent Health Care. ACOG Committee Opinion Number 760: dysmenorrhea and endometriosis in the adolescent. Obstet Gynecol. 2018;132(6):e249-e258.

17. Practice Committee of the American Society for Reproductive Medicine. Treatment of pelvic pain associated with endometriosis: a committee opinion. Fertil Steril. 2014;101(4):927-35. https://www. ncbi.nlm.nih.gov/pubmed/24630080

18. Dunselman GAJ, Vermeulen N, Becker C, et al. ESHRE guideline: management of women with endometriosis. Hum Reprod. 2014;29(3):400-12. https://academic.oup.com/humrep/article-abstract/ 29/3/400/707776

19. Lamvu G, Soliman AM, Manthena SR, Gordon K, Knight J, Taylor HS. Patterns of prescription opioid use in women with endometriosis. Obstet Gynecol. 2019;133(6):1120-30. https://insights.ovid.com/ crossref?an=00006250-201906000-00008
20. Madsen AM, Stark LM, Has P, Emerson JB, Schulkin J, Matteson KA. Opioid knowledge and prescribing practices among obstetrician-gynecologists. Obs Gynecol. 2018;131:150-7. https://apps. deadiversion.usdoj.gov/

21. Estes SJ, Soliman AM, Johns B, Lamvu G. Opioid utilization following endometriosis diagnosis: retrospective analysis of more than 100,000 women. Obstet Gynecol. 2019;133(5):1.

22. Chou R, Turner JA, Devine EB, et al. The effectiveness and risks of long-term opioid therapy for chronic pain: a systematic review for a National Institutes of Health Pathways to Prevention Workshop. Ann Intern Med. 2015;162(4):276-86.

23. National Academies of Sciences, Engineering, and Medicine; Health and Medicine Division; Board on Health Sciences Policy; Committee on Pain Management and Regulatory Strategies to Address Prescription Opioid Abuse. Trends in opioid use, harms, and treatment. In: Phillips JK, Ford MA, Bonnie RJ, editors. Pain management and the opioid epidemic: balancing societal and individual benefits and risks of prescription opioid use. Washington DC: National Academies Press; 2017.

24. Hepp Z, Lage MJ, Espaillat R, Gossain VV. The association between adherence to levothyroxine and economic and clinical outcomes in patients with hypothyroidism in the US. J Med Econ. 2018;21(9):912-9.

25. Baek S, Park SH, Won E, Park YR, Kim HJ. Propensity score matching: a conceptual review for radiology researchers. Korean J Radiol. 2015;16(2):286. https://doi.org/10.3348/kjr.2015.16.2.286.

26. Lunt M. Selecting an appropriate caliper can be essential for achieving good balance with propensity score matching. Am J Epidemiol. 2014;179(2): 226-35. https://doi.org/10.1093/aje/kwt212.

27. Basu A, Polsky D, Manning WG. Estimating treatment effects on healthcare costs under exogeneity: is there a 'magic bullet'? Heal Serv Outcomes Res Methodol. 2011;11(1-2):1-26. https://doi.org/10. 1007/s10742-011-0072-8.

28. Casciano JP, Dotiwala ZJ, Martin BC, Kwong WJ. The costs of warfarin underuse and nonadherence in patients with atrial fibrillation: a commercial insurer perspective. J Manag Care Pharm. 2013;19(4):302-16. https://doi.org/10.18553/jmcp. 2013.19.4.302.

29. As-Sanie S, Soliman AM, Evans K, Erpelding N, Lanier R, Katz N. Healthcare utilization and cost burden among women with endometriosis by opioid prescription status in the first year after diagnosis: a retrospective claims database analysis. 
J Med Econ. 2020;1:1-7. https://doi.org/10.1080/ 13696998.2019.1707212.

30. Orhurhu V, Olusunmade M, Urits I, et al. Trends of opioid use disorder among hospitalized patients with chronic pain. Pain Pract. 2019;19(6):656-63.

31. Deyo RA, Von KM, Duhrkoop D. Opioids for low back pain. BMJ. 2015;350:g6380.

32. Todd A, Akhter N, Cairns J-M, et al. The Pain Divide: a cross-sectional analysis of chronic pain prevalence, pain intensity and opioid utilisation in England. BMJ Open. 2018;8(7):e023391.

33. Miller A, Sanderson K, Bruno R, Breslin M, Neil A. Chronic pain, pain severity and analgesia use in
Australian women of reproductive age. Women Birth. 2019;32(2):e272-e278278.

34. Simoens S, Dunselman G, Dirksen C, et al. The burden of endometriosis: costs and quality of life of women with endometriosis and treated in referral centres. Hum Reprod. 2012;27(5):1292-9. https:// doi.org/10.1093/humrep/des073.

35. Soliman AM, Yang H, Du EX, Kelley C, Winkel C. The direct and indirect costs associated with endometriosis: a systematic literature review. Hum Reprod. 2016;31(4):712-22. https://doi.org/10. 1093/humrep/dev335.

36. Koltermann KC, Dornquast C, Ebert AD, Reinhold T. Economic burden of endometriosis: a systematic review. Ann Reprod Med Treat. 2017;2(2):1015. 